\title{
SGLT2 inhibition alleviated hyperglycemia, glucose intolerance, and dumping syndrome-like symptoms in a patient with glycogen storage disease type la: a case report
}

Daisuke Katayama ${ }^{1}$, Hiroo Baba ${ }^{2}$, Takashige Kuwabara ${ }^{3}$, Jun Kido ${ }^{4}$, Hiroshi Mitsubuchi ${ }^{5}$, Shirou Matsumoto ${ }^{4^{*}}$ (0) and Kimitoshi Nakamura ${ }^{4}$

\begin{abstract}
Background: Glycogen storage disease (GSD) type la is a glycogenesis disorder with long-term complications such as hepatomegaly and renal dysfunction and is caused by congenital loss of glucose-6-phosphatase (G6Pase) expression. G6Pase is essential for the final step of gluconeogenesis and glycogenolysis, and its deficiency causes clinical hypoglycemia in the fasting state during infancy. Contrastingly, patients also show blood glucose trends and glucose intolerance similar to those in type II diabetes. Owing to the contrasting presentation of hypoglycemia with glucose intolerance, glucose control in patients remains a challenge, requiring management of both fasting hypoglycemia and post-prandial hyperglycemia.
\end{abstract}

Case presentation: The patient was a 45-year old Asian (Japanese) woman who showed disease onset at 3 years of age, when hypoglycemia and hepatomegaly were observed, and GDS type la was diagnosed by the lack of G6Pase activity. Over the past 45 years, she presented hyperglycemia and dumping syndrome like symptoms (a feeling of fullness, even after eating just a small amount, abdominal cramping, nausea, sweating, flushing, or light-headedness and rapid heartbeat) at 2 hours after food intake. Her liver and kidney dysfunction also worsened over time. Treatment with exercise combined with a sodium-glucose co-transporter 2 inhibitor and an alpha glucosidase inhibitor alleviated her glucose intolerance and dumping syndrome-like symptoms, without increasing hypoglycemic events.

Conclusion: This case suggests SGLT2 inhibitor as a promising candidate for treating glucose intolerance in GSD type la without worsening of hypoglycemia.

Keywords: GSD type la, Glucose intolerance, SGLT2 inhibitor

\section{Background}

Glycogen storage disease (GSD) type Ia is an autosomal

\footnotetext{
*Correspondence: s-pediat@gpo.kumamoto-u.ac.jp

${ }^{4}$ Department of Pediatrics, Graduate School of Medical Sciences,

Kumamoto University, 1-1-1 Honjo, Kumamoto City, Kumamoto Prefecture 860-8556, Japan

Full list of author information is available at the end of the article
}

recessive disorder caused by dysfunction of the gene encoding glucose-6-phosphatase (G6Pase), a microsomal membrane component protein that is a critical enzyme in the final step of glycolysis and glycogenesis. G6Pase deficiency leads to hypoglycemia and accumulation of glycogen in several tissues, such as the muscle, kidney, and liver. Hypoglycemia is known to improve gradually because of G6Pase beta [1]. Contrastingly, patients also original author(s) and the source, provide a link to the Creative Commons licence, and indicate if changes were made. The images or other third party material in this article are included in the article's Creative Commons licence, unless indicated otherwise in a credit line to the material. If material is not included in the article's Creative Commons licence and your intended use is not permitted by statutory regulation or exceeds the permitted use, you will need to obtain permission directly from the copyright holder. To view a copy of this licence, visit http://creativecommons.org/licenses/by/4.0/. The Creative Commons Public Domain Dedication waiver (http://creativeco mmons.org/publicdomain/zero/1.0/) applies to the data made available in this article, unless otherwise stated in a credit line to the data. 
present glucose intolerance and dynamic plasma glucose levels, similar to those in type 2 diabetes, and parallel treatment of these contrasting conditions remains a challenge.

The sodium-glucose co-transporter 2 (SGLT2) inhibitor is a selective inhibitor that prevents glucose reabsorption by the proximal renal tube and corrects blood glucose levels to prevent glucose toxicity. Hypoglycemia is rare with the clinical usage of SGLT2 inhibitors because the other subtype of the inhibitor, SGLT1, continues to remain active and prevents extreme hypoglycemia. Several recent clinical trials indicated that SGLT2 inhibition is an effective strategy for diabetes mellitus and concluded that it (1) facilitates reduction of body weight and visceral fat, (2) prevents progressive kidney disease, and (3) improves liver function in non-alcoholic steatohepatitis (NASH) occurring with diabetes mellitus. All the complications mentioned above are also observed In GSD type Ia and a previous case report indicated that SGLT2 inhibitor improved diabetes mellitus in GSD type Ia [2].

In this context, we present here a case of successful alleviation GSD type Ia symptoms using a combination of exercise and an SGLT2 inhibitor.

\section{Case presentation}

The patient was a 45-year-old Asian (Japanese) woman, who presented polycystic ovarian syndrome, hypertension, hyper-urinary acid, bladder stone, urinary stone, progressive renal dysfunction, and lipid abnormality. When she was 3 years old, she visited our hospital because of hypoglycemia, liver enzyme elevation, and hepatomegaly. She was diagnosed as having GSD type Ia based on the loss of G6Pase activity in the liver $(<0.3 \mu \mathrm{mol} / \mathrm{minute} / \mathrm{g}$ tissue $)$.

In the first stage of life ( 3 years to 6 years), she needed frequent feedings and a night time cornstarch regimen until 7 years of age. After 8 years of age, her hypoglycemia improved and her glucose levels could be maintained with cornstarch intake twice a day. However, she had several complications such as kidney stones and hepatic adenomas with hepatomegaly.

At 20 years of age, her BMI increased (to 24.2) and she presented hyperglycemia after food intake (Fig. 1). The blood glucose dynamics indicated type 2 diabetes mellitus as described in Fig. 2 [Fasting glucose: 123 mg/ $\mathrm{dl}$, homeostatic model assessment of insulin resistance (HOMA-IR) 9.23]. Therefore, cornstarch feeding at night was stopped.

At 40 years of age, she presented hyperglycemia (200$260 \mathrm{mg} / \mathrm{dl}$ after feeding and dumping syndrome-like symptoms such as nausea, general fatigue, and dorsal pain). Moreover, the dumping syndrome-like symptoms worsened, resulting in poor quality of life. At first, she misunderstood that the complication was related to hypoglycemia and thus increased feeding, leading to an increase in body weight (maximum BMI was 26.4). Laboratory tests indicated elevated triglycerides $(880 \mathrm{mg} /$ dl) and abnormal liver function tests (Fig. 3). Magnetic resonance imaging (MRI) of the abdomen revealed multiple liver adenomas with diffuse steatosis. Investigation of diabetes showed an insulin level of $68 \mu \mathrm{IU} / \mathrm{ml}$ (normal range: $\leqq 18.7 \mu \mathrm{IU} / \mathrm{ml}$ ), with fasting blood glucose levels of $126 \mathrm{mg} / \mathrm{dl}$ (normal range: $70-114 \mathrm{mg} / \mathrm{dl}$ ). HOMA IR was calculated as $22.1(N<2.5)$, indicating severe insulin resistance.

At first, she attempted lifestyle modifications such as a lower carbohydrate diet, elongation of feeding time, and exercise. However, her condition did not improve. To avoid severe hypoglycemia and improve liver function, she was experimentally treated with luseogliflozin hydrate additionally, an SGLT2 inhibitor, at a dose of $2.5 \mathrm{mg}$ daily, after obtaining informed consent. After this intervention, she decreased her cornstarch intake, and her dumping syndrome-like symptoms disappeared completely. In addition, her body weight (BMI 21) and insulin resistance both decreased remarkably (HOMA-IR 4.49; Fig. 3).

\section{Discussion}

GSD1 is characterized by severe fasting hypoglycemia because of the lack of G6Pase- $\alpha$, but several studies have indicated that patients could demonstrate glucose production [3-5]. This recovery may be related to the widespread G6Pase- $\beta$ expression in the body [6]. GSD-Ia children show hypoglycemia, but with age, their endogenous glucose production rate improves, starting from $50 \%$ of the normal in young GSD-Ia patients, reaching $67-100 \%$ of the normal in adult GSD-Ia patients [3-5]. Because muscle mass increases with age, forming $20 \%$ of the body weight in a newborn, $36 \%$ in adolescence, and $40-45 \%$ of adulthood [6], the muscle G6Pase- $\beta$ / G6PT complex may be the source of some or all of the extra blood glucose. Upon undergoing such an agerelated change in the muscle volume as well as visceral fat and due to fatty liver and increased BMI because of frequent feeding, patients show insulin resistance and their blood glucose level dynamics are similar to those in type 2 diabetes. The reason for glucose resistance and hyperglycemia in GSD type Ia is unclear, but seems to be caused by frequent feeding, night time feeding, raw cornstarch, body weight gain, liver dysfunction, and renal dysfunction, all of which could cause insulin resistance and abnormal endogenous glucose production. Frequent hypoglycemia could also induce (1) downregulation of insulin/glucagon ratio leading to the release of 


\section{Cross-sectional Growth Chart for Girls (0-18 yrs)}

(The 2000 National Growth Survey on Preschool Children \& School Health Statistics Research)

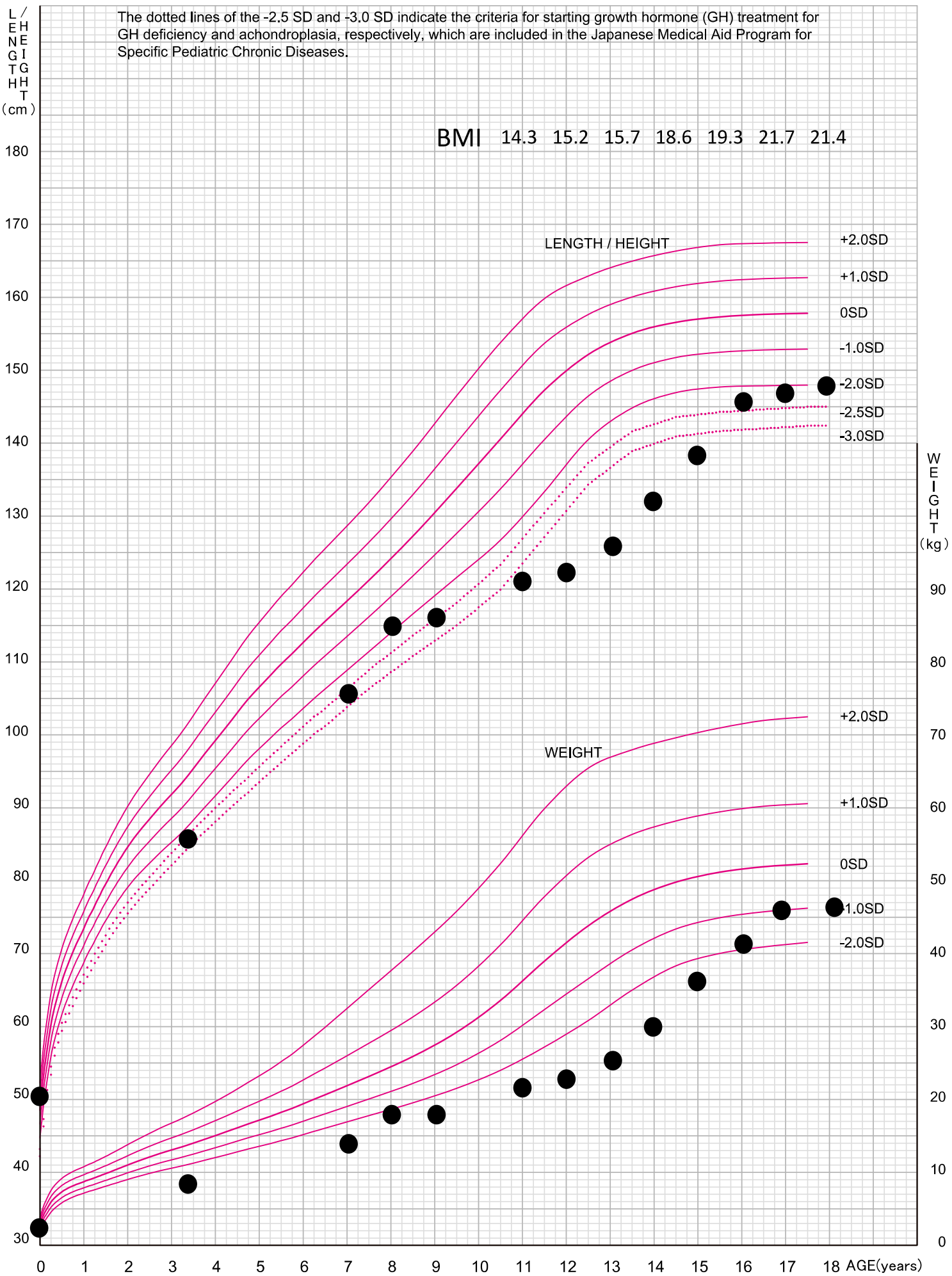

Fig. 1. Growth curve 


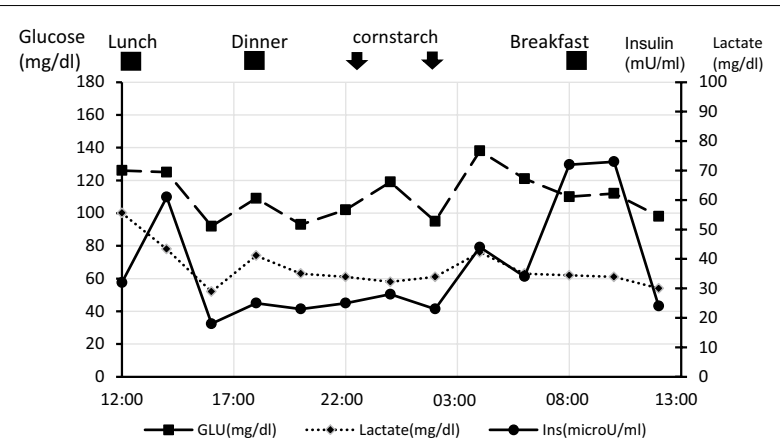

Fig. 2. Daily blood sugar fluctuation

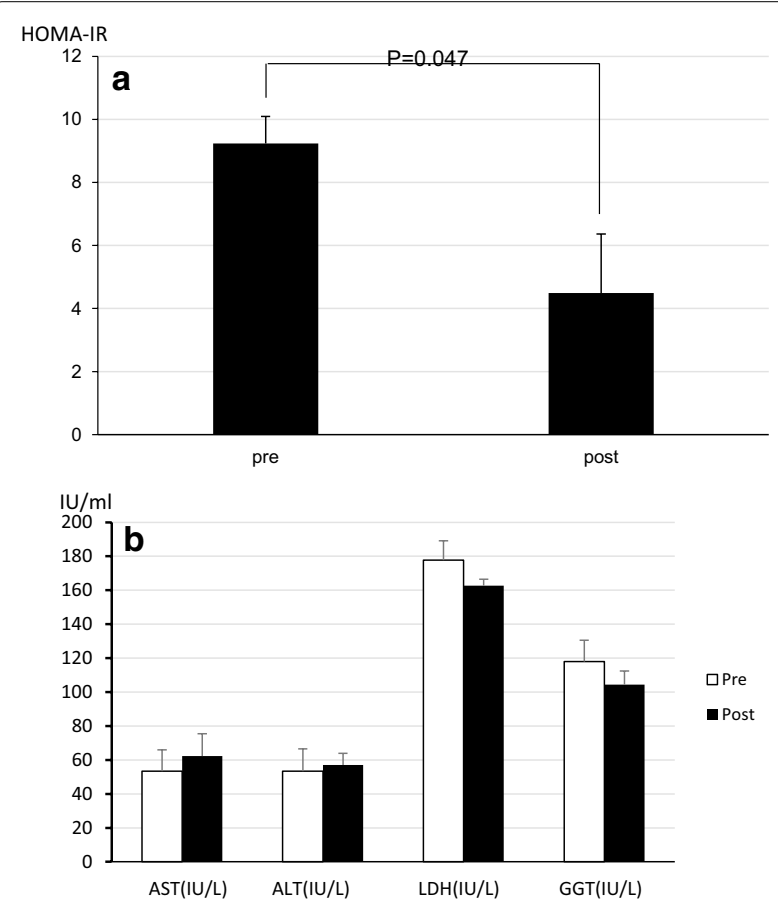

Fig. 3. Changes in Laboratory tests before and after treatment

free fatty acids, and (2) stimulation of glycogenesis in the liver leading to increased malonyl $\mathrm{Co} \mathrm{A}$ and inhibition of beta oxidation. Fatty liver in GSD type Ia is also thought to be caused by these mechanisms [7]. In contrast, excessive carbohydrate, which is needed to prevent hypoglycemia, is stored as glycogen in the liver, causing non-alcoholic fatty liver disease (NAFLD). It is reported that $69.8 \%$ of patients with NAFLD presented a glucose intolerance pattern [8]. In our patient, NAFLD/NASH since teenage and body weight gain were undoubtedly related to insulin resistance. Therefore, she was treated with an SGLT2 inhibitor, which could inhibit glucose reabsorption in the proximal renal tubule, release excessive glucose into urine and correct the plasma glucose levels. In addition, hypoglycemia is not expected because SGLT1 is still active and capable of preventing hypoglycemia. Preclinical studies indicate that the SGLT2 inhibitor could reduce insulin resistance, visceral fat, and body weight. A large clinical study in the UK (DAPA-HF study) indicated that the SGLT2 inhibitor could reduce the risk of cardiovascular death [9]. Another global clinical trial (DAPA-CKD Study, Phase III) indicated that an SGLT2 inhibitor (dapagliflozin) reduced the risk of a composite of a sustained decline in the estimated GFR of at least $50 \%$, end-stage kidney disease, or death from renal or cardiovascular causes [10]. Further, A prospective, singlearm trial (LEAD trial) indicated that Luseogliflozin could be a novel promising agent for treating patients with T2DM and NAFLD [11].

In our case, the SGLT2 inhibitor showed good performance in suppressing the dumping syndromelike symptoms mainly by alleviating hyperglycemia after feeding. In hypoglycemia, the SGLT2 inhibitor could reduce episodes of hypoglycemia and decrease between-meal eating, which may cause loss of body weight. Laboratory data related to NAFLD/NASH remained unchanged after intervention, but we consider that these may require a long-term treatment for improving.

\section{Conclusion}

Our case indicates that the SGLT2 inhibitor may be a potential candidate medication for GSD type Ia with insulin resistance and diabetes.

\section{Abbreviations}

GSD: Glycogen storage disease type la; SGLT2: Sodium-glucose co-transporter 2; BMI: Body mass index; DM: Diabetes mellitus; NASH: Non-alcoholic steatohepatitis; NAFLD: Non-alcoholic fatty liver disease; G6Pase: Glucose-6 phosphatase; G6PT: Glucose-6-phosphate transporter.

\section{Acknowledgements Not applicable.}

\section{Authors' contributions}

All authors participated in the literature search, chart review, writing and editing of the manuscript. All authors read and approved the final manuscript.

\section{Funding}

This study was supported in part by a Grant-in-Aid for Research on Rare and Intractable Diseases, Health and Labor Sciences Research; a Grant-in-Aid for Pediatric Research from the Ministry of Health, Labour and Welfare; a Grant-inAid from Japan Agency for Medical Research and Development; and a Grantin-Aid for Scientific Re-search from the Ministry of Education, Culture, Sports, Science, and Technology.

Availability of data and materials

All data used during this study are included in this published article.

Ethics approval and consent to participate

Ethics approval was obtained (reference No. 2160) from the Kumamoto University Research Ethical Committee. 


\section{Consent for publication}

Written informed consent was obtained from the patient for publication of this case report and any accompanying images. A copy of the written consent form is available for review by the Editor-in-Chief of this journal.

\section{Competing interests}

The authors declare that they have no competing interests.

\section{Author details}

${ }^{1}$ Department of Pediatrics, Kumamoto University Hospital, Honjo 1-1-1, Kumamoto City, Japan. ${ }^{2}$ Department of Endocrinology, Beppu Hospital, Saifu 1-6-23, Dazaifu City, Japan. ${ }^{3}$ Department of Nephrology, Graduate School of Medical Sciences, Kumamoto University, Honjo 1-1-1, Kumamoto City, Japan. ${ }^{4}$ Department of Pediatrics, Graduate School of Medical Sciences, Kumamoto University, 1-1-1 Honjo, Kumamoto City, Kumamoto Prefecture 860-8556, Japan. ${ }^{5}$ Division of Neonatology, Kumamoto University Hospital Honjo 1-1-1, Kumamoto City, Japan.

Received: 13 May 2020 Accepted: 28 December 2020

Published online: 16 February 2021

\section{References}

1. Shieh JJ, Pan CJ, Mansfield BC, Chou JY. A glucose-6-phosphate hydrase. Widely expressed outside the liver. Can explain age dependent resolution of hypoglycemia in glycogen storage disease type la. J Biol Chem. 2003:278:47098-103.

2. Cohn A, Ohri A. Diabetes mellitus in a patient with glycogen storage disease type la: a case report. J Med Case Rep. 2017;11(1):319.

3. Powell RC, Wentworth SM, Brandt IK. Endogenous glucose production in type I glycogen storage disease. Metabolism. 1981;30:443-50.

4. Tsalikian E, Simmons P, Gerich JE, Howard C, Haymond MW. Glucose production and utilization in children with glycogen storage disease type 1. Am J Physiol. 1984:247:E513-9.
5. Collins JE, Bartlett K, Leonard JV, Aynsley-Green A. Glucose production rates in type 1 glycogen storage disease. J Inherit Metab Dis. 1990;13(2):195-206.

6. Shieh JJ, Pan CJ, Mansfield BC, Chou JY. A potential new role for muscle in blood glucose homeostasis. J Biol Chem. 2004;279(25):26215-9.

7. Bandsma RH, Smit GP, Kuipers F. Disturbed lipid metabolism in glycogen storage disease type 1. Eur J Pediatr. 2002;161:S65-9.

8. Fukuda T, Hamaguchi M, Kojima T, Hashimoto Y, Ohbora A, Kato T, Nakamura N, Fukui M. The impact of non-alcoholic fatty liver disease on incident type2 diabetes mellitus in non-overweight individuals. Liver Int. 2016;36:275-83.

9. McMurray JJV, Solomon SD, Inzucchi SE, Køber L, Kosiborod MN, Martinez FA, Ponikowski P, Sabatine MS, Anand IS, Bělohlávek J, Böhm M, Chiang CE, Chopra VK, de Boer RA, Desai AS, Diez M, Drozdz J, Dukát A, Ge J, Howlett JG, Katova T, Kitakaze M, Ljungman CEA, Merkely B, Nicolau JC, O'Meara E, Petrie MC, Vinh PN, Schou M, Tereshchenko S, Verma S, Held C, DeMets DL, Docherty KF, Jhund PS, Bengtsson O, Sjöstrand M, Langkilde AM, DAPA-HF Trial Committees and Investigators. Dapagliflozin in patients with heart failure and reduced ejection fraction. N Engl J Med. 2019;381:1995-2008

10. Heerspink HJL, Stefánsson BV, Correa-Rotter R, Chertow GM, Greene T, Hou FF, Mann JFE, McMurray JJV, Lindberg M, Rossing P, Sjöström CD, Toto RD, Langkilde AM, Wheeler DC, DAPA-CKD Trial Committees and Investigators. Dapagliflozin in patients with chronic kidney disease. N Engl J Med. 2020;383(15):1436-46 (2020 Sep 24).

11. Sumida Y, Murotani K, Saito M, Tamasawa A, Osonoi Y, Yoneda M, Osonoi T. Effect of luseogliflozin on hepatic fat content in type 2 diabetes patients with non-alcoholic fatty liver disease: a prospective, single-arm trial (LEAD trial). Hepatol Res. 2019;49:64-71.

\section{Publisher's Note}

Springer Nature remains neutral with regard to jurisdictional claims in published maps and institutional affiliations.
Ready to submit your research? Choose BMC and benefit from:

- fast, convenient online submission

- thorough peer review by experienced researchers in your field

- rapid publication on acceptance

- support for research data, including large and complex data types

- gold Open Access which fosters wider collaboration and increased citations

- maximum visibility for your research: over $100 \mathrm{M}$ website views per year

At BMC, research is always in progress.

Learn more biomedcentral.com/submissions 